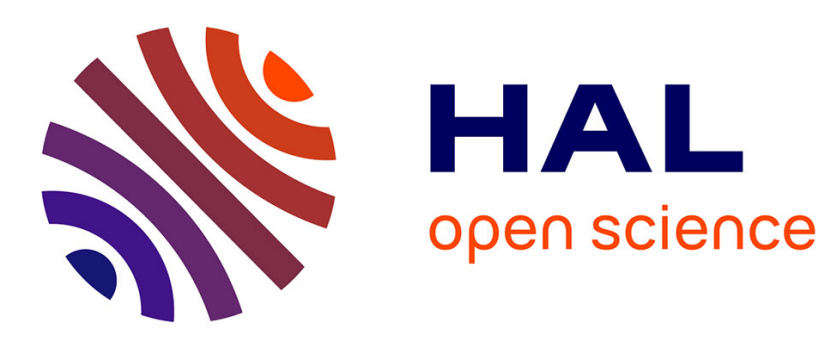

\title{
Characteristics of pain in patients with pituitary adenomas: A cross-sectional study
}

Sarah Dallel, Laurent Devoize, Igor Tauveron, Bruno Pereira, Pierre Clavelou, Salwan Maqdasy, Xavier Moisset, Radhouane Dallel

\section{- To cite this version:}

Sarah Dallel, Laurent Devoize, Igor Tauveron, Bruno Pereira, Pierre Clavelou, et al.. Characteristics of pain in patients with pituitary adenomas: A cross-sectional study. European Journal of Pain, In press, 10.1002/ejp.1721. hal-03126328

\section{HAL Id: hal-03126328 \\ https://hal.uca.fr/hal-03126328}

Submitted on 14 Feb 2021

HAL is a multi-disciplinary open access archive for the deposit and dissemination of scientific research documents, whether they are published or not. The documents may come from teaching and research institutions in France or abroad, or from public or private research centers.
L'archive ouverte pluridisciplinaire HAL, est destinée au dépôt et à la diffusion de documents scientifiques de niveau recherche, publiés ou non, émanant des établissements d'enseignement et de recherche français ou étrangers, des laboratoires publics ou privés. 


\section{Characteristics of pain in patients with pituitary adenomas: a cross-sectional study}

Running title: Migraine prevalence in PA patients

Sarah DALLEL, Laurent DEVOIZE, Igor TAUVERON, Bruno PEREIRA, Pierre CLAVELOU, Salwan MAQDASY, Xavier MOISSET*, Radhouane DALLEL*

Université Clermont Auvergne, CHU Clermont-Ferrand, Inserm, Neuro-Dol, F-63000 Clermont-

$$
\text { Ferrand, France }
$$

* Co-last authors

\section{Corresponding author:}

Radhouane DALLEL, radhouane.dallel@uca.fr

INSERM/UCA U1107, Neuro-Dol: Trigeminal pain and Migraine

Faculté de Chirurgie Dentaire, 2 rue de Braga, 63100 Clermont-Ferrand, France

Tel: (33) 473177313

Funding sources: none

Conflicts of interest: The authors have no conflicts of interests to declare.

Significance: Migraine headaches and neuropathic pain are more common in PA patients than in the general population and are generally poorly treated. A systematic screening for migraine should be done by physicians in daily practice to provide adequate therapeutics. 


\section{ABSTRACT}

Background: This study determines the prevalence and particularities of headache and pain with neuropathic characteristics (NC) in a large French group of patients with pituitary adenoma (PA).

Methods: Analysis of validated self-administered questionnaires, radiological characteristics, and treatment strategies of PA was performed.

Results: Of the 221 sent questionnaires, 146 could be used for statistical analysis, 50\% of which were completed by women. Among responders, $58.9 \%$ had pain: $30.1 \%$ migraine, $15.7 \%$ pain with NC, and $13.1 \%$ other types of pain. Migraine was more common in patients with PA than in the general population $(30.1 \%$ vs $21.3 \%, p=0.010)$ and attacks received appropriate treatment for less than $20 \%$ of these patients. Furthermore, the prevalence of chronic migraine was much higher than in the general population $(6.8 \%$ vs $2.2 \%, p=0.003)$. Neuropathic pain was also more frequent in PA patients than in the general population $(15.8 \%$ vs $6.9 \%, p<0.001)$. Neuropathic pain was most often located in the extremities and was frequently described as an "electric shock", "numbness", or "pinsand-needles". Multivariate analyses linked migraine to younger age, anxiety, pain with NC, and a visible tumor on MRI, regardless of its invasiveness or secretory nature.

Conclusions: Migraine headaches and neuropathic pain are more frequent and disabling in PA patients than in the general population. Both types of pain are comorbid in PA patients and are poorly treated. Migraine is associated with the presence of a tumor. Thus, biological mechanisms of this relationship need to be characterized to design optimal treatments for these individuals. 


\section{INTRODUCTION}

Pituitary adenomas (PAs) are frequent intracranial tumors. Headache is a frequent complaint in such patients (Suri and Dougherty, 2018). The prevalence of headache varies from 37 to $70 \%$, depending on the inclusion criteria and data collection (Abe et al., 1998; Levy et al., 2004). Various types of headaches, including migraine, cluster headache, SUNCT (short-lasting unilateral neuralgiform headache with conjunctival injection and tearing), hemicrania continua, paroxysmal hemicrania, and "trigeminal neuralgia", have been described in the literature (Levy et al., 2005). However, very few studies have assessed the prevalence of each type of headache in PA patients. Moreover, whether PAs and headache are related is still a subject of debate, as both conditions may simply coexist owing to their high prevalence (Gravdahl et al., 2016). The few studies to address this issue were retrospective, included few patients, and provided contradictory evidence (Suri and Dougherty, 2018). Indeed, there have been no controlled studies comparing the prevalence and phenotype of headache in treated and untreated patients. In addition, headache alone is still debated as an indication to treat pituitary tumors, despite good results in several published surgical case series (Fleseriu et al., 2009).

In addition to headaches, body pain has also been described by patients with PAs. In acromegaly, excess growth hormone $(\mathrm{GH})$ leads to persistent joint-related complaints (Biermasz et al., 2005). The prevalence of arthralgia has been reported to vary from 50 to $90 \%$ of patients with acromegaly (Albarel et al., 2019; Biermasz et al., 2005; Hoskuldsdottir et al., 2015; Mercado et al., 2004; Miller et al., 2008). A recent large-scale study reported that $65 \%$ of patients with PA suffered from bodily pain (Dimopoulou et al., 2014). In this study, most patients (80\%) had nociceptive pain. Nevertheless, although peripheral polyneuropathy has been frequently described for patients with acromegaly $(50 \%)$, there are no data concerning pain with neuropathic characteristics (NCs) in patients with PA (Jamal et al., 1987).

In France, little is known about the prevalence and characteristics of pain in patients with PA. We thus aimed to: i) characterize the prevalence and clinical characteristics of pain, with a particular focus on migraine headache and pain with NC, and ii) identify the main factors associated with the presence and severity of these two types of pain in a large French cohort of patients with PA. 


\section{MATERIALS AND METHODS}

\section{Ethic}

The study was performed in accordance with the Declaration of Helsinki, Good Clinical Practice, and applicable regulatory requirements. This observational survey received approval of the French National Data Protection Commission (CNIL, authorization number 0142). All participants gave written informed consent.

\section{Patients}

In total, 221 patients treated at Clermont-Ferrand University Hospital between 2011 and 2015 for PA were asked to participate in the study. A validated questionnaire was sent to all patients and a short cover letter inviting patients to participate in the study accompanied the questionnaire. Each questionnaire was sent with a postage-paid return envelope ant it was clearly stated that those answering "no" to the first question should return the questionnaire without completing the following pages. There was only one postal survey sent to each patient (no reminders).

\section{Survey questionnaire}

The questionnaire was deliberately simple and designed to be completed in less than 15 min. Validated questionnaires were used to limit the risk of bias. Previous studies proved the ease of use of a similar questionnaire (Moisset et al., 2013, 2017).

The first question was "Are you suffering or have you suffered during the last month from pain or headache?" Only participants who responded positively to this question were invited to answer the first part of the questionnaire. The first part of the questionnaire concerned the identification of migraine (Lantéri-Minet et al., 2005a; Moisset et al., 2013, 2017). The short form of the headache impact test (HIT-6) was used to estimate the impact of the headache (Kosinski et al., 2003). A score $\geq 60$ indicates a severe impact on daily life.

The second part of the questionnaire concerned other types of pain. The subject answered the two questions (including seven items) from the DN4 interview questionnaire concerning the characteristic of their pain (Bouhassira et al., 2008). A score of 1 was given to each positive item and a score of 0 to each negative item. Respondents with total score $\geq 3 / 7$ items were considered to have the characteristics of neuropathic pain, with a sensitivity of $81.6 \%$ and a specificity of $85.7 \%$ according to a previous validation (Bouhassira et al., 2008). A body diagram allowed identification 
of the locations of the pain. We used the results of the study by Bouhassira et al. (2008), which assessed the prevalence of pain with NC in the general population, as a historical control. We also used the results of the study by Lantéri-minet et al. (2005b), which assessed the prevalence of migraine in the general population. We assessed the severity of pain and the impact on daily functions using the short form of the Brief Pain Inventory (Cleeland and Ryan, 1994). The results of the four pain intensity scores were pooled together in the Pain Severity Index and the seven items concerning the interference of pain were pooled together in the Pain Interference Index. Finally, The hospital anxiety and depression (HAD) scale was used to evaluate mood and anxiety (Zigmond and Snaith, 1983), with higher scores indicating higher levels of anxiety or depression. The percentage of patients with anxiety or depression are expressed by the relative proportions of patients exhibiting HAD anxiety or depression scores $>7$ (both scales spanning the range 0-21).

\section{Clinical and biological data}

The radiological and biological characteristics of PA and treatment options were obtained from the patients' medical files. Information on smoking habits and usual treatment were obtained from the questionnaire.

\section{Statistical analysis}

All analyses were performed using Stata software (Version 13, StataCorp, College Station, TX) for a two-sided Type I error of $5 \%$. Patient characteristics are expressed as the means \pm standarddeviation or medians (interquartile range) for continuous variables and as numbers and associated percentages for categorical variables. Continuous variables were compared between independent groups (with/without pain, with/without migraine, with/without NC, and migraine vs. headache) using the Student t-test or Mann-Whitney test Comparisons between independent groups were carried out using the Chi-squared or Fischer's exact test for categorical variables. The factors associated with migraine were determined by constructing a multivariable logistic regression model using the stepwise approach (backward and forward) on covariates fixed according to univariate results and clinical relevance. Multicollinearity and interactions between covariates received particular attention. Results are expressed as odds-ratios and 95\% confidence intervals (95\%CI). As described by some authors (Bender and Lange, 2001), systematic correction of type I error was not applied. 


\section{RESULTS}

\section{Patient Characteristics}

Of the 221 questionnaires sent, 146 (66.1\%) were completed and assessed. The main characteristics of the population and various sub-groups are presented in Figure 1. Of the 146 patients included in this study, 50\% were women and the mean age was $59.2 \pm 16.1$ years (range, 16 to 90 years). The clinical and demographic characteristics of responders and non-responders were broadly similar, except for age ( $52.9 \pm 17.9$ years; range, 17 to 93 years, $n=75)$, which was significantly lower for non-responders $(p=0.006)$.

The PAs were non-functioning in 61 patients (41.7\%), prolactin-secreting in $27(18.5 \%), \mathrm{GH}-$ secreting in $32(19.9 \%)$, ACTH-secreting in $21(14.4 \%)$, and TSH-secreting in one $(0.7 \%)$. Four patients had mixed PAs. Fifty (34\%) patients had macroadenoma, 38 (26\%) microadenoma, and 51 (35\%) no visible tumor on MRI. Such information was absent for seven patients. Most patients received only surgical treatment (54\%) and $28 \%$ received a combination of surgical and medical treatment and/or radiotherapy. The remaining patients received either medical treatment $(18 \%)$ or radiotherapy ( $1 \%)$ alone. Surgery was performed, on average, $7.5 \pm 8.2$ years before the study. The mean age of operated patients was $52.4 \pm 15.1$ years.

Among the non-responding patients, the PAs were non-functioning in 31 patients $(41.3 \%)$, prolactin-secreting in $21(28.0 \%)$, GH-secreting in $15(20.0 \%)$, and ACTH-secreting in eight (10.7\%). Thirty-six (48\%) patients had macroadenoma, 19 (25.3\%) microadenoma, and 16 (21.3\%) no visible tumor on MRI.

\section{Overall pain}

Among the 146 patients, $86(58.9 \%)$ reported pain, amongst whom women predominated ( $p=$ 0.044) (Table 1). Pain was most frequently associated with prolactin- and growth hormone-secreting PAs, anxiety, depression, and pituitary surgery (Table 1). Among the 86 patients with pain, 79 $(54.1 \%)$ reported headaches. Forty-nine $(33.5 \%)$ patients reported pain other than headache, among whom, $23(15.8 \%)$ reported pain with NC.

\section{Migraine}

The headache characteristics are shown in Table 2 . Of the 44 patients with migraine, $10.2 \%$ fulfilled all international headache society criteria for strict migraine and $19.9 \%$ fulfilled all but one criterion, giving a total prevalence of $31.1 \%$ for probable migraine (Table 3 ). This prevalence is significantly 
higher than the $21.3 \%$ reported in the general French population (Lantéri-Minet et al., 2005a) (OR $=1.59 ; 95 \%$ CI 1.11 to $2.27 ; p=0.010$ ), with an increase in all strata, whatever the age or gender.

Patients with migraine had headaches of moderate intensity (6.4 \pm 1.9$)$. Among them, 10 patients had migraines $>15$ days per month $(6.8 \%$ of all respondents). This prevalence is significantly higher $(p=0.03)$ than that in the general French population $(1.4 \%-2.2 \%)$. A very high proportion of migraine patients (79.6\%) were taking analgesic treatment and $20.5 \%$ were taking two or more different classes of analgesics, but only eight patients (18.2\%) received adequate treatment during attacks (NSAIDs and/or triptan) (Table 3).

The patients suffering from migraine were younger than non-migraine patients $(p<0.001)$ and had higher anxiety $(10.7 \pm 4.0$ vs $6.4 \pm 4.0, p<0.001)$ and depression scores $(7.5 \pm 4.2$ vs $5.1 \pm$ $4.0, p=0.003)$. The proportion of subjects with anxiety $(32.7 \%$ vs $78.0 \%$; OR $=7.22 ; 95 \% \mathrm{CI}$, 2.94 to $19.35 ; p<0.001)$ and depression $(25.3 \%$ vs $46.3 \% ; \mathrm{OR}=2.54 ; 95 \% \mathrm{CI}, 1.16$ to $5.86 ; p=$ 0.017) was significantly higher among migraine sufferers than in the population of non-migraine sufferers. The average total HIT- 6 score was $61.4 \pm 5.8$ (range: $46-75, n=42$ ) and 31 of 42 patients (73.8\%) with migraine had a HIT-6 score $\geq 60$, indicating that their headaches had a severe impact on their daily lives.

The most common tumor associated with migraine was prolactinoma ( $n=15,34.1 \%)$. Supraand intra-sellar extension, cavernous sinus invasion, and a history of pituitary surgery or radiotherapy were not associated with migraine.

On multivariate logistic analyses (Table 4$)$, younger age $(p=0.003)$, anxiety $(p=0.002)$, pain with NC $(p=0.007)$, and a visible tumor on MRI, regardless of its invasiveness $(p=0.042)$, were significantly and independently associated with migraine, whereas prolactinoma and depression were not.

\section{Pain with neuropathic characteristics}

Overall, 49 patients $(33.6 \%)$ experienced non-headache pain. Twenty-three patients (Table 5) reported pain with NC $(15.8 \%)$, whereas the prevalence is only $6.9 \%$ (Bouhassira et al., 2008) in the general population ( $O R=2.55 ; 95 \% C I, 1.55$ to $4.02 ; p<0.001$ ). Pain with $\mathrm{NC}$ was increased for both men and women, but was increased only in patients aged under $50(\mathrm{OR}=8.38 ; 95 \% \mathrm{CI}$, 4.72 to $14.86, \mathrm{p}<0.001)$. Patients with pain with NC were more frequently women $(p=0.044)$ and it was frequently associated with migraines $(p=0.001)$ (Table 5). The mean pain intensity, as measured by the VAS score, was $5.3 \pm 2.2$. A larger proportion of patients with pain with NC took 
analgesics than those without pain with NC. Three of the seven pain descriptors were particularly used by patients presenting NC: "pins and needles", "electric shock", and "numbness". The pain was mainly located in the upper limbs. However, neuropathic pain did not correlate with the characteristics (invasiveness, secretion, type of treatment) of the pituitary tumor. 


\section{DISCUSSION}

This study is the first to assess the prevalence and clinical characteristics of pain, with a particular focus on headache and neuropathic pain, in a large group of French PA patients treated either surgically and/or medically. We found the prevalence of migraine and pain with NC to be higher in PA patients than in the general population. Furthermore, migraine was associated with young age, anxiety, pain with NC, and a visible tumor on MRI, regardless of its invasiveness or secretory activity.

This study confirms that pain is a very common symptom in PA patients. Almost $60 \%$ of patients in this study reported pain in the previous month. A similar overall prevalence has been previously reported (Dimopoulou et al., 2014). The pain consisted of neuropathic pain for $15.8 \%$ and migraine for $30.1 \%$ of patients. Moreover, pain with NC and migraine were associated in $10.3 \%$ of our cohort.

Headache is one of the most frequent complaints of PA patients. The overall prevalence of headache in our cohort was 54\%, well within the previously reported range (Suri and Dougherty, 2018). Migraine was the most common type of headache (56\%), as in all but one prospective studies (Levy et al., 2005; Siegel et al., 2017; Wang et al., 2009; Yu et al., 2017; Zhang et al., 2019). Of note, tension-type headache was more common than migraine in one study (Schankin et al., 2012). The overall prevalence of migraine in our cohort was $30 \%$, thus 1.6 times higher than in the general French population (Lantéri-Minet et al., 2005a). Indeed, the reported prevalence of migraine varies from 11 to 42\% (Hayashi et al., 2019; Siegel et al., 2017; Yu et al., 2017; Zhang et al., 2019). However, it is noteworthy that the highest migraine prevalence was found in the study that enrolled only patients with non-functioning PA (Yu et al., 2017). To account for a putative non-response bias, we may consider that all non-responders were pain-free, in both our cohort and previous historical controls. In the study by Lantéri-Minet et al. (2005a), 70.2\% of the mailed questionnaires (2245 out of 15000 ) could be analyzed, leading to a migraine prevalence of $15.0 \%$. As 44/221 is different from $2245 / 15000(p=0.041)$, such analysis tends to confirm the validity of the present data.

The prevalence of chronic migraine in our PA patients was $6.8 \%$, much higher than that in the general population (1.4-2\%) (Natoli et al., 2010). Although the prevalence of migraine, especially chronic migraine, was high for our PA patients, optimal treatment for migraine was rarely prescribed. Thus, only $18 \%$ of our migraine population received specific treatment for attacks and none, preventive treatment. This was probably linked to the absence of a diagnosis. Based on published guidelines for acute migraine treatment, non-steroidal anti-inflammatory drugs (NSAIDs) should be used as first-line treatment (Evers et al., 2009; Marmura et al., 2015). 
The HIT-6 questionnaire is now widely used as a screening instrument to assess the impact of headache on the life of patients. The mean scores on the HIT-6 scale of headache impact, as well as the proportion of subjects scoring $\geq 60$ on this scale, corresponding to a severe/very severe impact, were significantly higher in the migraine group. Thus, our data in this specific population of PA patients highlight the fact that migraine has a strong negative impact on the quality of life of patients.

We found that a risk factor for migraine was younger age, as already shown by others (Hayashi et al., 2019; Schankin et al., 2012). However, such an association was not observed in patients with non-functioning PAs (Yu et al., 2017). Schankin et al. (2012) suggested that headache is more likely to be the first symptom of a brain tumor in younger patients than in older patients, probably because of generalized brain atrophy in the latter case, which may also affect the pituitary gland. However, this explanation is unlikely in most cases as the pituitary is enclosed in a very confined space and even the slightest increase can induce stretching of meningeal membranes (from the cavernous sinuses or diaphragma sellae), potentially inducing headaches. Alternatively, the occurrence of a migraine-like tumor-induced headache may decrease with age, as does the prevalence of migraine (Bigal et al., 2006).

Another risk factor for migraine in PA patients was anxiety. The proportion of anxious patients in our cohort was significantly higher in the migraine than non-migraine population. This confirms the often reported strong association between migraine and psychiatric disorders (Lantéri-Minet et al., 2005b, 2005a; Peres et al., 2017). Importantly, migraine sufferers in our PA population displayed higher HAD scores for anxiety than those in the general population (Lantéri-Minet et al., 2005b, 2005a), indicating a greater disability. The observed difference could stem directly from the pituitary lesion or indirectly from the effect of hormonal disturbances on neural circuits or neurotransmission (Weitzner et al., 2005). According to Weitzner et al. (2005), the hypothalamic-pituitary axis would affect the control of behavior by the prefrontal cortex through its rich connections with limbic structures.

We found that pain with NC was frequent (16\% of patients) in PA patients. There are known mechanisms for neuropathic pain in PA: polyneuropathy and compression neuropathies due to median nerve edema in acromegaly (Chanson et al., 2009) and peripheral neuropathies due to a high incidence of diabetes mellitus in Cushing's disease (Pivonello et al., 2007). However, the prevalence in our study was much higher than that reported in a previous study ( $1 \%$ of PA patients) using the painDETECT questionnaire (Dimopoulou et al., 2014). It cannot be ruled out that the selfadministered DN4 questionnaire, used here, led to an overestimation of the prevalence of 
neuropathic pain or a potential misclassification (Timmerman et al., 2017). Nonetheless, the same questionnaire was used in the general population, used as controls, and the sensitivity and specificity of this French version of the questionnaire was good with the self-administered questionnaire, with a sensitivity of $81.6 \%$ and a specificity of $85.7 \%$ (Bouhassira et al., 2008). As in the general neuropathic pain population (Bouhassira et al., 2008), pain with NC was often located in the upper and lower limbs and described as numbness, electric shocks, and pins-and-needles. Importantly, none of these patients received appropriate neuropathic pain treatment (Finnerup et al., 2015; Moisset et al., 2020), indicating that their analgesic treatment should be reconsidered. Pain with NC was significantly associated with a higher risk of migraine in our PA patients. This is the first study showing a correlation between migraine and neuropathic pain in PA patients. Similarly, pain with NC and migraine have been found to both be present in $32 \%$ of patients with multiple sclerosis (Moisset et al., 2013). However, we cannot rule out an overestimation of this association due to the subjective reporting method employed in our study.

The pathophysiology of headache in PA patients is thus far unknown. Putative mechanisms include those that are mainly mechanical and/or biochemical. Although our univariate analyses showed a significant association between migraine and prolactinoma, such an association vanished after adjustment. Furthermore, although numerous case reports on headaches in patients with prolactinoma (Levy et al., 2003; Massiou et al., 2002) or acromegaly (Abe et al., 1998) have been published, no prospective clinical study has ever demonstrated a correlation between headache and adenoma-related endocrine dysfunction. In addition, headaches have also been reported to correlate with tumor size and invasion into the cavernous sinus (Gondim et al., 2009; Yu et al., 2017), but other reports were unable to replicate these results (Abe et al., 1998; Levy et al., 2004; Schankin et al., 2012). Here, we report that migraine is associated with a visible residual tumor on MRI, regardless of its invasiveness. The biological mechanisms linking the presence of a tumor with migraine are unknown. Thus, future studies are needed to consolidate this relationship.

Our study had several limitations. First, we included a heterogeneous population with various tumor types and treatment methods. It would have been informative to know the pain status of our patients before treatment. Second, there was no information concerning the duration of pain. In accordance with previous studies, we classified patients with or without pain on the basis of selfreported pain during the previous month. Unfortunately, the duration of pain is rarely reported in other studies. Third, there was no information concerning the consumption of analgesics, which would have helped to discriminate between chronic migraine and medication overuse headaches. 
Fourth, patients did not undergo a physical examination to confirm the diagnosis of both migraine and neuropathic pain. However, the questionnaires used have been well-validated, even if their use may have led to a risk of overestimation or misclassification. Nonetheless, data from the general population were collected using the same methodology, allowing comparison. Finally, a bias due to non-response is possible. Nonetheless, a $66 \%$ response rate seems acceptable (Draugalis et al., 2008) and closed to the response rate from control studies, with a response rate of $70.2 \%$ in the study on migraine (Lantéri-Minet et al., 2005a) and 78.6\% in the study of neuropathic pain (Bouhassira et al., 2008).

\section{Conclusion}

Migraine headaches and neuropathic pain are frequent and disabling in PA patients. Their prevalence is higher than that reported in the general population. Both types of pain are comorbid in PA patients and are poorly treated. Importantly, migraine is associated with the presence of a tumor. Therefore, deciphering the biological mechanisms linked to pain should help in the design of optimal treatments for these individuals. 


\section{Acknowledgements}

This work was supported by funding from the Institut National de la Santé et de la Recherche Médicale (Inserm), Universite Clermont Auvergne (France), and CHU Clermont-Ferrand (France).

\section{Author Contributions}

SD: study concept and design, acquisition of data; analysis and interpretation of data; drafting of the manuscript. LD: study concept and design; critical revision of the manuscript for important intellectual content. IT: study concept and design, critical revision of the manuscript for important intellectual content. BP: analysis and interpretation of data; statistical analysis. PC: critical revision of the manuscript for important intellectual content. SM: critical revision of the manuscript for important intellectual content. XM: study concept and design; analysis and interpretation of data; drafting of the manuscript. RD: study concept and design; analysis and interpretation of data; drafting of the manuscript, study supervision. All authors read and approved the final manuscript 


\section{REFERENCES}

Abe, T., Matsumoto, K., Kuwazawa, J., Toyoda, I., and Sasaki, K. (1998). Headache associated with pituitary adenomas. Headache 38, 782-786.

Albarel, F., Elaraki, F., and Delemer, B. (2019). Daily life, needs and expectations of patients with acromegaly in France: An on-line survey. Ann. Endocrinol. 80, 110-116.

Bender, R., and Lange, S. (2001). Adjusting for multiple testing--when and how? J. Clin. Epidemiol. $54,343-349$.

Biermasz, N.R., Pereira, A.M., Smit, J.W.A., Romijn, J.A., and Roelfsema, F. (2005). Morbidity after long-term remission for acromegaly: persisting joint-related complaints cause reduced quality of life. J. Clin. Endocrinol. Metab. 90, 2731-2739.

Bigal, M.E., Liberman, J.N., and Lipton, R.B. (2006). Age-dependent prevalence and clinical features of migraine. Neurology 67, 246-251.

Bouhassira, D., Lantéri-Minet, M., Attal, N., Laurent, B., and Touboul, C. (2008). Prevalence of chronic pain with neuropathic characteristics in the general population. Pain 136, 380-387.

Chanson, P., Salenave, S., Kamenicky, P., Cazabat, L., and Young, J. (2009). Pituitary tumours: acromegaly. Best Pract. Res. Clin. Endocrinol. Metab. 23, 555-574.

Cleeland, C.S., and Ryan, K.M. (1994). Pain assessment: global use of the Brief Pain Inventory. Ann. Acad. Med. Singapore 23, 129-138.

Dimopoulou, C., Athanasoulia, A.P., Hanisch, E., Held, S., Sprenger, T., Toelle, T.R., RoemmlerZehrer, J., Schopohl, J., Stalla, G.K., and Sievers, C. (2014). Clinical characteristics of pain in patients with pituitary adenomas. Eur. J. Endocrinol. 171, 581-591.

Draugalis, J.R., Coons, S.J., and Plaza, C.M. (2008). Best practices for survey research reports: a synopsis for authors and reviewers. Am. J. Pharm. Educ. 72, 11.

Evers, S., Afra, J., Frese, A., Goadsby, P.J., Linde, M., May, A., Sándor, P.S., and European Federation of Neurological Societies (2009). EFNS guideline on the drug treatment of migraine-revised report of an EFNS task force. Eur. J. Neurol. 16, 968-981.

Finnerup, N.B., Attal, N., Haroutounian, S., McNicol, E., Baron, R., Dworkin, R.H., Gilron, I., Haanpää, M., Hansson, P., Jensen, T.S., et al. (2015). Pharmacotherapy for neuropathic pain in adults: a systematic review and meta-analysis. Lancet Neurol. 14, 162-173.

Fleseriu, M., Yedinak, C., Campbell, C., and Delashaw, J.B. (2009). Significant headache improvement after transsphenoidal surgery in patients with small sellar lesions. J. Neurosurg. 110, 354-358. 
Gondim, J.A., de Almeida, J.P.C., de Albuquerque, L.A.F., Schops, M., Gomes, E., and Ferraz, T. (2009). Headache associated with pituitary tumors. J. Headache Pain 10, 15-20.

Gravdahl, G.B., Tronvik, E.A., Fougner, S.L., and Solheim, O. (2016). Pituitary Adenoma and Nonacute Headache: Is There an Association, and Does Treatment Help? World Neurosurg. 92, 284291.

Hayashi, Y., Sasagawa, Y., Oishi, M., Kita, D., Misaki, K., Fukui, I., Tachibana, O., and Nakada, M. (2019). Contribution of Intrasellar Pressure Elevation to Headache Manifestation in Pituitary Adenoma Evaluated With Intraoperative Pressure Measurement. Neurosurgery 84, 599-606.

Hoskuldsdottir, G.T., Fjalldal, S.B., and Sigurjonsdottir, H.A. (2015). The incidence and prevalence of acromegaly, a nationwide study from 1955 through 2013. Pituitary 18, 803-807.

Jamal, G.A., Kerr, D.J., McLellan, A.R., Weir, A.I., and Davies, D.L. (1987). Generalised peripheral nerve dysfunction in acromegaly: a study by conventional and novel neurophysiological techniques. J. Neurol. Neurosurg. Psychiatry 50, 886-894.

Kosinski, M., Bayliss, M.S., Bjorner, J.B., Ware, J.E., Garber, W.H., Batenhorst, A., Cady, R., Dahlöf, C.G.H., Dowson, A., and Tepper, S. (2003). A six-item short-form survey for measuring headache impact: the HIT-6. Qual. Life Res. Int. J. Qual. Life Asp. Treat. Care Rehabil. 12, 963-974.

Lantéri-Minet, M., Valade, D., Géraud, G., Chautard, M.H., and Lucas, C. (2005a). Migraine and probable migraine--results of FRAMIG 3, a French nationwide survey carried out according to the 2004 IHS classification. Cephalalgia Int. J. Headache 25, 1146-1158.

Lantéri-Minet, M., Radat, F., Chautard, M.-H., and Lucas, C. (2005b). Anxiety and depression associated with migraine: influence on migraine subjects' disability and quality of life, and acute migraine management. Pain 118, 319-326.

Levy, M.J., Matharu, M.S., and Goadsby, P.J. (2003). Prolactinomas, dopamine agonists and headache: two case reports. Eur. J. Neurol. 10, 169-173.

Levy, M.J., Jäger, H.R., Powell, M., Matharu, M.S., Meeran, K., and Goadsby, P.J. (2004). Pituitary volume and headache: size is not everything. Arch. Neurol. 61, 721-725.

Levy, M.J., Matharu, M.S., Meeran, K., Powell, M., and Goadsby, P.J. (2005). The clinical characteristics of headache in patients with pituitary tumours. Brain J. Neurol. 128, 1921-1930.

Marmura, M.J., Silberstein, S.D., and Schwedt, T.J. (2015). The acute treatment of migraine in adults: the american headache society evidence assessment of migraine pharmacotherapies. Headache 55, 3-20. 
Massiou, H., Launay, J.M., Levy, C., El Amrani, M., Emperauger, B., and Bousser, M.G. (2002). SUNCT syndrome in two patients with prolactinomas and bromocriptine-induced attacks. Neurology 58, 1698-1699.

Mercado, M., Espinosa de los Monteros, A.L., Sosa, E., Cheng, S., Mendoza, V., Hernández, I., Sandoval, C., Guinto, G., and Molina, M. (2004). Clinical-biochemical correlations in acromegaly at diagnosis and the real prevalence of biochemically discordant disease. Horm. Res. 62, 293299.

Miller, A., Doll, H., David, J., and Wass, J. (2008). Impact of musculoskeletal disease on quality of life in long-standing acromegaly. Eur. J. Endocrinol. 158, 587-593.

Moisset, X., Ouchchane, L., Guy, N., Bayle, D.J., Dallel, R., and Clavelou, P. (2013). Migraine headaches and pain with neuropathic characteristics: Comorbid conditions in patients with multiple sclerosis: Pain 154, 2691-2699.

Moisset, X., Bommelaer, G., Boube, M., Ouchchane, L., Goutte, M., Dapoigny, M., Dallel, R., Guttmann, A., Clavelou, P., and Buisson, A. (2017). Migraine prevalence in inflammatory bowel disease patients: A tertiary-care centre cross-sectional study. Eur. J. Pain Lond. Engl. 21, 15501560.

Moisset, X., Bouhassira, D., Avez Couturier, J., Alchaar, H., Conradi, S., Delmotte, M.H., LanteriMinet, M., Lefaucheur, J.P., Mick, G., Piano, V., et al. (2020). Pharmacological and nonpharmacological treatments for neuropathic pain: Systematic review and French recommendations. Rev. Neurol. (Paris) 176, 325-352.

Natoli, J.L., Manack, A., Dean, B., Butler, Q., Turkel, C.C., Stovner, L., and Lipton, R.B. (2010). Global prevalence of chronic migraine: a systematic review. Cephalalgia 30, 599-609.

Peres, M.F.P., Mercante, J.P.P., Tobo, P.R., Kamei, H., and Bigal, M.E. (2017). Anxiety and depression symptoms and migraine: a symptom-based approach research. J. Headache Pain 18, 37.

Pivonello, R., De Martino, M.C., De Leo, M., Tauchmanovà, L., Faggiano, A., Lombardi, G., and Colao, A. (2007). Cushing's syndrome: aftermath of the cure. Arq. Bras. Endocrinol. Metabol. 51, 13811391.

Schankin, C.J., Reifferscheid, A.K., Krumbholz, M., Linn, J., Rachinger, W., Langer, S., Sostak, P., Arzberger, T., Kretzschmar, H., and Straube, A. (2012). Headache in patients with pituitary adenoma: clinical and paraclinical findings. Cephalalgia Int. J. Headache 32, 1198-1207.

Siegel, S., Weber Carneiro, R., Buchfelder, M., Kleist, B., Grzywotz, A., Buslei, R., Bingel, U., Brabant, G., Schenk, T., and Kreitschmann-Andermahr, I. (2017). Presence of headache and headache 
types in patients with tumors of the sellar region-can surgery solve the problem? Results of a prospective single center study. Endocrine 56, 325-335.

Suri, H., and Dougherty, C. (2018). Clinical Presentation and Management of Headache in Pituitary Tumors. Curr. Pain Headache Rep. 22, 55.

Timmerman, H., Steegers, M.A.H., Huygen, F.J.P.M., Goeman, J.J., van Dasselaar, N.T., Schenkels, M.J., Wilder-Smith, O.H.G., Wolff, A.P., and Vissers, K.C.P. (2017). Investigating the validity of the DN4 in a consecutive population of patients with chronic pain. PloS One 12, e0187961.

Wang, S.-J., Hung, C.-W., Fuh, J.-L., Lirng, J.-F., and Hwu, C.-M. (2009). Cranial autonomic symptoms in patients with pituitary adenoma presenting with headaches. Acta Neurol. Taiwanica $18,104-112$.

Weitzner, M.A., Kanfer, S., and Booth-Jones, M. (2005). Apathy and pituitary disease: it has nothing to do with depression. J. Neuropsychiatry Clin. Neurosci. 17, 159-166.

Yu, B., Ji, N., Ma, Y., Yang, B., Kang, P., and Luo, F. (2017). Clinical characteristics and risk factors for headache associated with non-functioning pituitary adenomas. Cephalalgia Int. J. Headache $37,348-355$.

Zhang, Y., Pan, Q., Jiang, H., Yang, G., Chen, L., Qin, G., and Zhou, J. (2019). A prospective study of headache and neuropeptides in patients with pituitary adenomas. Cephalalgia Int. J. Headache $39,1049-1057$

Zigmond, A.S., and Snaith, R.P. (1983). The hospital anxiety and depression scale. Acta Psychiatr. Scand. $67,361-370$. 


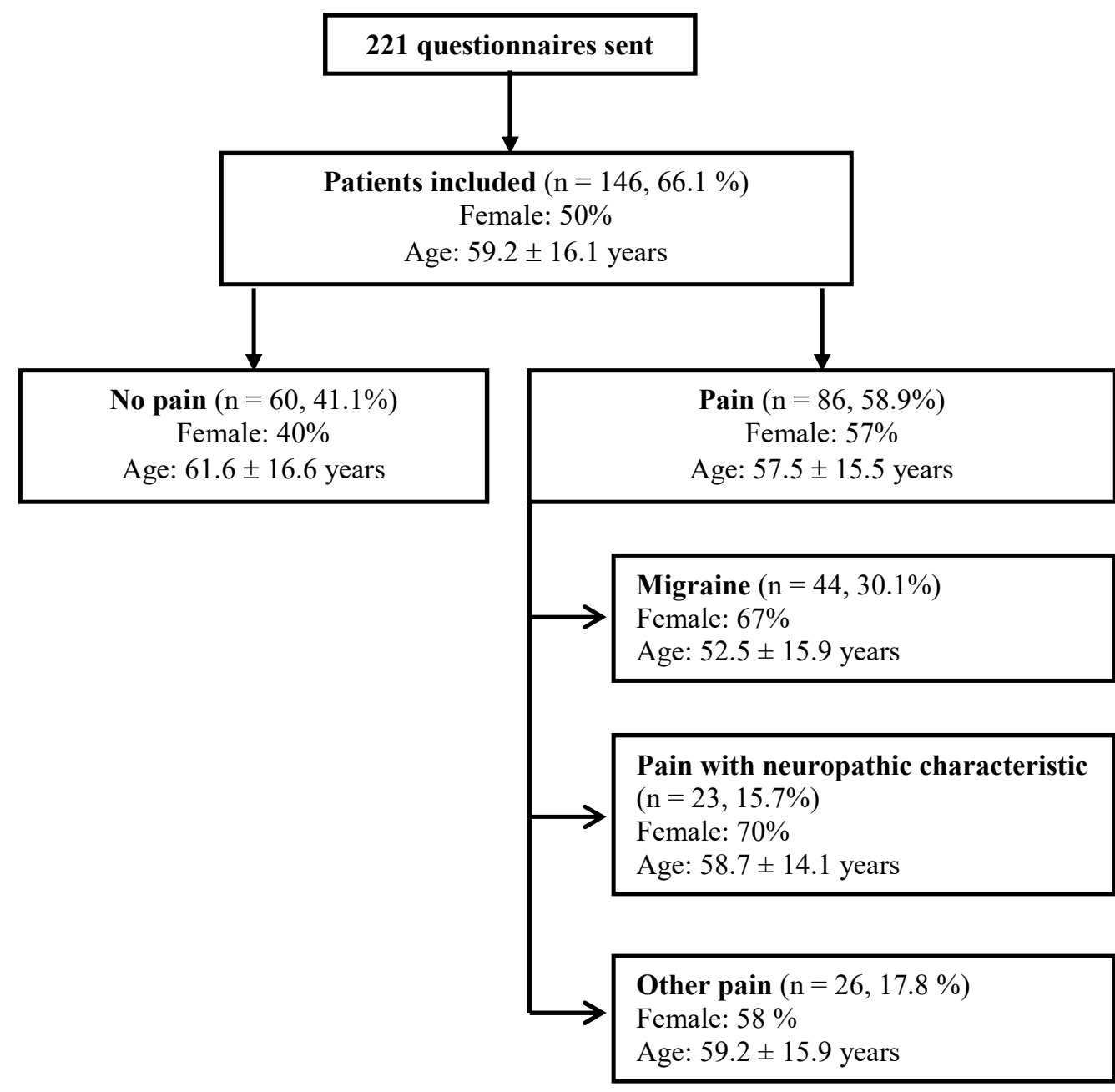

Figure 1. Main characteristics of the cohort and the different sub-groups. Variables are presented as mean \pm standard deviation. 
Table 1. Factors associated with pain in patients with pituitary adenoma

\begin{tabular}{llll}
\hline Variables & \multicolumn{2}{l}{$\begin{array}{l}\text { Patient with pain } \\
(\mathrm{n}=86)\end{array}$} & $\begin{array}{l}\text { Patient without pain } \\
(\mathrm{n}=60)\end{array}$ \\
\hline Female sex, (\%) & 67.1 & 32.9 & $\mathbf{0 . 0 4 4}$ \\
Age \pm SD, years & $57.5 \pm 15.5$ & $61.6 \pm 16.6$ & 0.135 \\
Smoking, \% (n)* & $19.8(17)$ & $11.7(7)$ & 0.252 \\
HAD-Anxiety / 21 & $8.0[5.0-12.2]$ & $6.0[3.0-8.5]$ & $<\mathbf{0 . 0 0 1}$ \\
HAD-Depression / 21 & $7.0[3.0-10.0]$ & $4.0[2.0-7.0]$ & $<\mathbf{0 . 0 0 1}$ \\
Presence of pituitary tumor, \% (n)* & $62.8(54)$ & $56.7(34)$ & 0.332 \\
Tumor invasiveness, \% (n)* & & & \\
$\quad$ Cavernous sinus invasion & $14.0(12)$ & $23.3(14)$ & 0.526 \\
$\quad$ Infrasellar extension & $3.5(3)$ & $8.3(5)$ & 0.831 \\
$\quad$ Suprasellar extension & $15.1(13)$ & $16.7(10)$ & 0.228 \\
Type of secretion, \% (n) & & & \\
$\quad$ Non-functioning & $38.4(33)$ & $46.7(28)$ & 0.317 \\
$\quad$ Prolactin & $25.6(22)$ & $8.3(5)$ & $\mathbf{0 . 0 0 8}$ \\
$\quad$ Growth hormone & $16.3(14)$ & $30.0(18)$ & $\mathbf{0 . 0 4 9}$ \\
$\quad$ Adrenocorticotropic hormone & $16.3(14)$ & $11.7(7)$ & 0.435 \\
Pituitary surgery, \% (n)* & $61.6(53)$ & $81.7(49)$ & $\mathbf{0 . 0 1 6}$ \\
Pituitary radiotherapy, \% (n)* & $17.4(15)$ & $13.3(8)$ & 0.488 \\
\hline
\end{tabular}

Variables are presented as percentage (numbers), mean \pm standard deviation or median and interquartile range. HAD: hospital anxiety and depression scale. *Missing data 
Table 2. Characteristics of headache

\begin{tabular}{llll}
\hline Variables & $\begin{array}{l}\text { Migraine } \\
(\mathrm{n}=44)\end{array}$ & $\begin{array}{l}\text { Headache } \\
(\mathrm{n}=35)\end{array}$ & $P$-value \\
\hline Unilateral location, \% (n) & $70.5(31)$ & $45.7(16)$ & $\mathbf{0 . 0 2 6}$ \\
Pulsating quality, \% (n) & $52.3(23)$ & $8.6(3)$ & $<\mathbf{0 . 0 0 1}$ \\
Aggravation by routine physical activity, \% (n) & $70.5(31)$ & $25.7(9)$ & $\mathbf{0 . 0 0 1}$ \\
Moderate or severe pain intensity, \% (n) & $84.1(37)$ & $60.0(21)$ & $\mathbf{0 . 0 1 6}$ \\
Nausea/vomiting, \% (n) & $40.9(18)$ & $5.7(2)$ & $<.001$ \\
Photo/phonophobia, \% (n) & $88.6(39)$ & $8.6(3)$ & $<\mathbf{0 . 0 0 1}$ \\
$>$ 4h when untreated, \% (n) & $59.1(26)$ & $82.9(29)$ & $<\mathbf{0 . 0 0 1}$ \\
\hline 72 h when untreated, \% (n) & $72.7(32)$ & 0.286
\end{tabular}

Variables are presented as percentage (numbers). 
Table 3. Factors associated with probable migraine in patients with pituitary adenoma.

\begin{tabular}{|c|c|c|c|}
\hline Variables & $\begin{array}{l}\text { Patients with } \\
\text { migraine } \\
(n=44)\end{array}$ & $\begin{array}{l}\text { Patients without migraine } \\
(\mathrm{n}=102)\end{array}$ & $P$-values \\
\hline Female sex, $(\%)$ & 64 & 44 & 0.030 \\
\hline Age, years & $54.0[37.2-65.5]$ & $63.5[53.7-72.0]$ & 0.001 \\
\hline Headache pain intensity /10 & $7[5-8]$ & $0[0-3]$ & $<0.001$ \\
\hline Number of days/month with headache & $7[4-15]$ & $0[0-1]$ & $<\mathbf{0 . 0 0 1}$ \\
\hline Chronic headache (>14days/month), \% (n) & $22.7(10)$ & $4.9(5)$ & 0.001 \\
\hline At least 1 analgesic, $\%(n)$ & $79.5(35)$ & $28.4(29)$ & $<\mathbf{0 . 0 0 1}$ \\
\hline At least 2 analgesics, $\%(n)$ & $20.5(9)$ & $3.9(4)$ & $<0.001$ \\
\hline Pain with NCs (DN4 $\geq 3 / 7), \%$ (n) & $34.1(15)$ & $7.8(8)$ & $<\mathbf{0 . 0 0 1}$ \\
\hline Other pain, $\%(n)$ & $68.2(30)$ & $18.6(19)$ & 0.042 \\
\hline Pain interference Index, $/ 10$ & $5.1[3.9-6.7]$ & $0.0[0.0-0.0]$ & $<0.001$ \\
\hline Pain severity Index, /10 & $4.7[3.4-5.8]$ & $0.0[0.0-0.0]$ & $<\mathbf{0 . 0 0 1}$ \\
\hline Smoking, $\%(n)^{*}$ & $21.4(9)$ & $15.5(15)$ & 0.393 \\
\hline HAD-Anxiety / 21 & $10.0[8.0-13.0]$ & $5.5[4.0-9.0]$ & $<0.001$ \\
\hline HAD-Depression / 21 & $7.0[4.5-10.5]$ & $4.0[2.0-8.0]$ & $<0.001$ \\
\hline Presence of tumor, $\%(n)^{*}$ & $75.6(31)$ & $58.2(57)$ & 0.052 \\
\hline \multicolumn{4}{|l|}{ Tumor invasiveness, $\%(\mathrm{n})^{*}$} \\
\hline Cavernous sinus invasion & $13.5(5)$ & $22.8(21)$ & 0.233 \\
\hline Infrasellar extension & $2.6(1)$ & $7.3(7)$ & 0.439 \\
\hline Suprasellar extension & $15(6)$ & $17.9(17)$ & 0.683 \\
\hline \multicolumn{4}{|l|}{ Type of secretion, \% (n) } \\
\hline Non-functioning & $31.8(14)$ & $46.1(47)$ & 0.108 \\
\hline Prolactin & $34.1(15)$ & $11.7(12)$ & 0.002 \\
\hline Growth hormone & $15.9(7)$ & $24.5(25)$ & 0.249 \\
\hline Adrenocorticotropic hormone & $15.9(7)$ & $13.7(14)$ & 0.730 \\
\hline Pituitary surgery, $\%(n)^{*}$ & $62.5(25)$ & $76.2(77)$ & 0.100 \\
\hline Pituitary radiotherapy, $\%(n)^{*}$ & $16.7(6)$ & $20.5(17)$ & 0.628 \\
\hline
\end{tabular}

Variables are presented as percentage (numbers), mean \pm standard deviation or median and interquartile range. HAD: hospital anxiety and depression scale. *Missing data. 
Table 4. Multivariate logistic analyses of potential risk factors for pituitary adenoma-associated migraine

\begin{tabular}{lcc}
\hline Variables & Odds Ratio, 95\% CI & $P$-value \\
\hline Age & $0.950[0.92-0.98]$ & $\mathbf{0 . 0 0 3}$ \\
HAD-Anxiety & $1.319[1.10-1.58]$ & $\mathbf{0 . 0 0 2}$ \\
HAD-Depression & $1.010[0.85-1.20]$ & 0.901 \\
Pain with neuropathic characteristic & $6.839[1.68-27.75]$ & $\mathbf{0 . 0 0 7}$ \\
Prolactinoma & $1.780[0.56-5.68]$ & 0.330 \\
Presence of tumor & $3.345[1.04-10.73]$ & $\mathbf{0 . 0 4 2}$ \\
\hline
\end{tabular}

CI: confidence interval; HAD: hospital anxiety and depression scale. 
Table 5. Factors associated with pain with neuropathic characteristics (NC) in patients with pituitary adenoma

\begin{tabular}{|c|c|c|c|}
\hline Variables & $\begin{array}{l}\text { Patient with NC } \\
(n=23)\end{array}$ & $\begin{array}{l}\text { Patient without } \mathrm{NC} \\
(\mathrm{n}=122)\end{array}$ & P-value \\
\hline Female sex, \% (n) & $69.6(16)$ & $46.7(65)$ & 0.044 \\
\hline Age $\pm \mathrm{SD}, \mathrm{y}$ & $58.7 \pm 14.1$ & $59.2 \pm 16.5$ & 0.872 \\
\hline Pain interference Index, /10 & $5.4[3.8-6.7]$ & $0[0.0-2.8]$ & $<0.001$ \\
\hline Pain severity Index, /10 & $5.0[2.8-5.8]$ & $0[0.0-3.3]$ & $<0.001$ \\
\hline \multicolumn{4}{|l|}{ Pain descriptors, \% (n) } \\
\hline Burning & $34.8(8)$ & $20(5)$ & 0.250 \\
\hline Painful cold & $30.4(7)$ & $4(1)$ & 0.020 \\
\hline Electric shock & $73.9(17)$ & $15.4(4)$ & $<0.001$ \\
\hline Tingling & $69.6(16)$ & $20(5)$ & 0.001 \\
\hline Pins and needles & $82.6(19)$ & $15.4(4)$ & $<0.001$ \\
\hline Itching & $56.5(13)$ & $23.1(6)$ & 0.016 \\
\hline Numbness & $69.6(16)$ & $15.4(4)$ & $<0.001$ \\
\hline \multicolumn{4}{|l|}{ Pain locations, $\%(n)^{*}$} \\
\hline Head & $35.0(7)$ & $26.9(7)$ & 0.555 \\
\hline Neck/shoulder & $35.0(7)$ & $34.6(9)$ & 0.978 \\
\hline Upper limb & $60.0(12)$ & $30.8(8)$ & 0.047 \\
\hline Thorax & $20.0(4)$ & $15.4(4)$ & 0.713 \\
\hline Abdomen & $15.0(3)$ & $7.7(2)$ & 0.640 \\
\hline Back & $55.0(11)$ & $30.8(8)$ & 0.098 \\
\hline Lower limb & $65.0(13)$ & $46.2(12)$ & 0.244 \\
\hline$\geq 3$ locations, $\%$ (n) & $45.0(9)$ & $30.8(8)$ & 0.322 \\
\hline Migraine, \% (n) & $26.1(6)$ & $7.4(9)$ & 0.007 \\
\hline At least one analgesic, \% (n) & $69.6(16)$ & $38.5(47)$ & 0.006 \\
\hline At least 2 analgesics, $\%$ (n) & $8.7(2)$ & $9(11)$ & 0.096 \\
\hline Other pain, $\%(n)^{*}$ & $100(23)$ & $42.6(26)$ & $<0.001$ \\
\hline Smoking, $\%(n)^{*}$ & $18.2(4)$ & $17.2(20)$ & 1.000 \\
\hline HAD-Anxiety / $21 \pm$ SD & $8.0[5.0-12.0]$ & $7.0[4.0-10.0]$ & 0.123 \\
\hline HAD-Depression / $21 \pm \mathrm{SD}$ & $7.0[4.0-10.0]$ & $5.0[2.0-8.0]$ & 0.088 \\
\hline Presence of tumor, $\%(n)^{*}$ & $52.4(11)$ & $65.8(77)$ & 0.238 \\
\hline \multicolumn{4}{|l|}{ Tumor invasiveness, $\%(\mathrm{n})^{*}$} \\
\hline Cavernous sinus invasion & $11.1(2)$ & $21.8(24)$ & 0.526 \\
\hline Infrasellar extension & $4.7(1)$ & $6.3(7)$ & 1.000 \\
\hline Suprasellar extension & $9.1(2)$ & $18.8(21)$ & 0.365 \\
\hline \multicolumn{4}{|l|}{ Type of secretion, \% (n) } \\
\hline Non-functioning & $26.1(6)$ & $44.3(54)$ & 0.104 \\
\hline Prolactin & $26.1(7)$ & $17.2(23)$ & 0.208 \\
\hline Growth hormone & $26.1(6)$ & $21.3(26)$ & 0.612 \\
\hline Adrenocorticotropic hormone & $8.6(3)$ & $15.5(19)$ & 0.756 \\
\hline Pituitary surgery, $\%(n)^{*}$ & $76.2(16)$ & $71.4(85)$ & 0.654 \\
\hline Pituitary radiotherapy, $\%$ (n)* & $16.7(3)$ & $20.0(20)$ & 1.000 \\
\hline
\end{tabular}

Variables are presented as percentage (numbers), mean \pm standard deviation or median and interquartile range. HAD: hospital anxiety and depression scale. *Missing data. 